\begin{abstract}
Mónica Ruiz Bañuls
Licenciada en Filología Hispánica por la Universidad de Alicante y Diplomada en Ciencias Religiosas por la Facultad de Teología San Vicente Ferrer de Valencia es investigadora del Departamento de Filología Española de la Universidad de Alicante, donde en la actualidad realiza su tesis doctoral. Está integrada en la unidad de investigación «Recuperaciones del mundo precolombino y colonial en el siglo XX hispanoamericano». $\mathrm{Ha}$ publicado diversos artículos sobre el teatro mexicano del siglo XIX. la utilización de discursos precolombinos en el teatro evangelizador y acerca de la labor de los evangelizadores franciscanos en Nueva España. Su línea de investigación actual está centrada en la utilización de diversos discursos de la literatura prehispánica (los huehuetlatolli) por parte de los misioneros franciscanos que llevaron a cabo el proceso evangelizador de México durante el siglo XVI.
\end{abstract}

\title{
LA DEVOCIÓN POPULAR GUADALUPANA EN LA TEATRALIDAD MEXICANA
}

\author{
MÓNICA RUIZ BAÑULS
}

\section{RESUMEN}

La irrupción del hecho guadalupano en diversas manifestaciones dramáticas a lo largo del acontecer histórico de México responde sin duda al hecho de que la teatralidad popular ha expresado siempre las luchas, tribulaciones y preocupaciones que han ido marcando el ritmo de las vivencias cotidianas e históricas de un pueblo.

En este sentido, la devoción a la Virgen de Guadalupe, patrona de México y símbolo de mexicanidad, se convierte en una manifestación de la identidad colectiva del pueblo, que no se limitará sólo a lo religioso sino que, como veremos en este trabajo, abarcará una dimensión social, ideológica y cultural que ha motivado durante siglos y, lo sigue haciendo en la actualidad, su notable presencia en las representaciones teatrales populares.

\section{POPULAR GUADALUPE DEVOTION IN MEXICAN HISTRIONICS}

\section{ABSTRACT}

The appearance of the Guadalupe event in many dramatic representations throughout historic occurrence in Mexico undoubtedly responds to the fact that popular drama has always expressed the struggles, tribulations and preoccupations which bave set the rhythm of everyday and historical events within a village.

In this sense, the devotion to the Virgin of Guadalupe, patron saint of Mexico and symbol of what it means to be Mexican, becomes a show of people's collective identity. This work demonstrates that this is not limited to the merely religious but also, includes a social, ideological and cultural dimension which for centuries has made and continues to make its notable presence felt in popular dramatic representations.

El teatro como objetivización sensible de unas creencias ancestrales, como encarnación del misterio de las cosas y la trascendencia de las conductas ha funcionado desde sus orígenes como un conjunto escénico en el que la historia humana y percepción de lo divino se han unido como expresión eficaz de un intercambio festi- vo. En este sentido, las manifestaciones teatrales que surgen en torno a la Virgen de Guadalupe, patrona de México y, sobre todo, símbolo de mexicanidad, encarnan perfectamente dicha simbiosis en la que estas representaciones se convierten en modos de expresión definidores de la identidad del pueblo mexicano. 
Desde este planteamiento, quiero acercarme en el presente trabajo al teatro guadalupano no desde la exhaustividad de análisis de un cuerpo documental ${ }^{1}$, sino desde la necesaria vinculación de estas manifestaciones a un marco de referencia más amplio relativamente poco estudiado: el de la religiosidad popular. Considero que la arraigada devoción a la Virgen de Guadalupe en México representa uno los puntos clave de dicha teatralidad: aquel que revelan las manifestaciones dramáticas guadalupanas como una forma de entender el mundo dentro de los contextos sociales y políticos en los que se han visto inmersas.

\section{DEL TEATRO EVANGELIZADOR AI TEATRO GUADALUPANO}

A finales del siglo XVI y, sin duda, estrechamente vinculadas a la institucionalización del culto guadalupano entre la población indígena, surgen una serie de piezas dramáticas relacionadas con la Virgen de Guadalupe ${ }^{2}$ que pueden ser consideradas como la evolución de un teatro evangelizador que, tras su manifiesto declive en esta época ${ }^{3}$, continuó desarrollándose en el ámbito popular indígena. En dicho contexto, este teatro fue absorbido y transformado para «terminar disolviéndose en sustancia folklórica, forma en que ha sobrevivido hasta nuestros días» ${ }^{4}$, de manera que estas manifestaciones aún hoy se pueden encontrar en muchas partes de México donde el ciclo navideño se inicia con alguna dramatización, más o menos extensa, de la aparición de la Virgen, con brevísimas pantomimas de Guadalupe revelándose al humilde indio Juan Diego o con representaciones completas de obras clásicas del teatro popular como Las Cuatro Apariciones de Nuestra Señora de Guadalupe

Ahora bien, considero que se hace necesario plantear brevemente el proceso histórico que da origen al guadalupanismo mexicano y que contribuirá sin duda a la mayor comprensión de la vigencia de esta temática en la teatralidad popular. Parto para ello de la reflexión de Edmundo O'Gorman's, quien plantea que la devoción guadalupana nace como fruto de los intereses personales de fray Alonso de Montúfar y del vigoroso empeño de este arzobispo por «remozar con aquella nueva imagen el viejo culto de substitución de la diosa Tonatzin» ${ }^{\top}$. Para este investigador, la extraña intervención de Montúfar en el hecho guadalupano y el apoyo incondicional del prelado hacia la imagen del Tepeyac res-

ponderían a un proyecto político y religioso muy concreto:

El objetivo de la corona española al enviar al teólogo dominico para ocupar la sede vacante de la diócesis de México era asentar con firmeza la autoridad episcopal y regalista de la Iglesia española que propugnaba por la estricta observancia de la

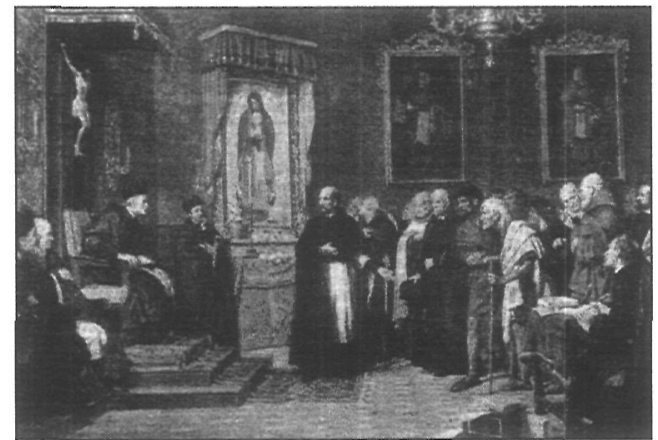

Informaciones de 1666. Cuadro José María Ibarrán. Pintado en 1873 para la Colegiata de Guadalupe.

legislación canónica; el mantenimiento del aparato ceremonial y ritual y el respeto a las tradiciones y costumbres de la devoción popular. Tal, pues, en términos muy generales es el programa con el que debía cumplir el señor Montúfar: el favor que le dispensó a la imagen de Tepeyac se explicaría en función de esa suprema finalidad 8 .

Todo este proceso es abordado por O'Gorman a través del estudio de la Información que el Señor Arzobispo de México D. Fray Alonso de Montúfar mandó practicar sobre un sermón que el 8 de septiembre de 1556 predicó fray Francisco de Bustamante acerca del culto de nuestra señora de Guadalupe?, donde se recoge la temprana polémica en torno a la validez del culto guadalupano. Fue con motivo de la celebración de la Natividad de María de 1556 cuando el reconocido predicador franciscano Francisco de Bustamante puso de manifiesto durante el sermón lo dañino del culto a la Virgen de Guadalupe, argumentando que «había sido inventada ayer» y que la imagen «había sido pintada por un

Existen diversas investigaciones que abordan este tema con detalle pero, sin duda, el trabajo de lectura casi obligada en este sentido sigue siendo el de Armando de María y Campos, La Virgen frente a las candilejas o El teatro guadalupano, México, Ediciones Populares, 1954

2

Estoy pensando por ejemplo en rextos como El coloquio de la Aparición, La conquista espiritual de la América por María Santísima de Guadalupe o El Portento Mexicano (cf. los datos aportados por
Fernando Horcasitas en "Las piezas teatrales en lengua náhuatl. Bibliografía descriptiva», Boletín Bibliográfico de Antropología (México), 1948, núm. XI, págs. 155-163 y María y Campos, op. cit., págs. 12-13).

3

Para más información sobre el declive del teatro evangelizador véase el capítulo "Causas de la decadencia del teatro misioneros en Beatriz Aracil Varón, El Teatro evangelizador: sociedad, culfura ideología en la Nueva España del siglo XVI, Roma, Bulzoni, 1999, págs. 521-557.
Juan José Arrom, El teatro de Hispanoamérica en la época colonial, La Habana, Anuario Bibliográfico Cubano, 1956 , pág. 50

5

Fernando Horcasitas recoge la existencia de esta representación en sus apuntes bibliográficos publicados recientemente por María Sten y Germán Viveros, Teatro náhuail II. Selección y estudio crítico de los materiales inéditos de Fernando Horcasitas (México, UNAM, 2004). Se pueden leer en sus anotaciones: "Las cuatro apariciones de la Virgen, autor anónimo. Representación que se hace en el barrio de Tecujapa el $10 \mathrm{de}$ diciembre de cada año. Organizada y dirigida por la srta. Guadalupe Loyo Sánchez, que vive en la calle de Francisco Zarco, en San Juan Coscomatepec. Ver recolección efectuada el 10 y 11 de 1951» (pág. 424; también recogida en $\mathrm{Ma}$ ría y Campos, op.cit., págs. 54 y ss.).

6

Edmundo O'Gorman, Destierro de sombras. Luz en el origen de la imagen y culto de Nuestra Señora de Guadalupe del Tepeyac México, UNAM, 1986

7 Ibidem, pág. 139

8

Ibidem, pág. 127.

9

Puede ser consultada de forma íntegra, versión paleográfica de fray Fidel de Jesús Chauvet, en (www.proyectoguadalupe. com).

La devoción popular guadalupana en la teatralidad mexicana MÓNICA RUIZ BAÑULS 


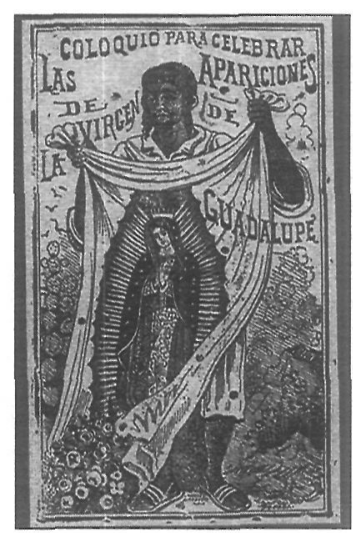

Celebraciones de Oaxaca de la Virgen de Guadalupe. Juan Diego llevando la tilma de la Virgen. 1992.

\section{0}

Información que el Señor Arzobispo de México D. Fray Alonso ed Montúfar mandó practicar sobre un sermón que el 8 de septiembre de 7556 predicó fray Francisco de Bustamante acerca del culto de nuestra señora de Guadalupe, versión paleográfica de fray Fidel de Jesús Chauvet, ibidem, folio $2 b$.

\section{1}

O’Gorman, op.cit., pág. 84.

\section{2}

Josefina Muriel de la Torre, La tradición de las pastorelas mexicanas, México, Ediciones Olivo, 1996, pág.13.

\section{3}

Término acuñado en la investigación hispanoamericanista actual por Robert Ricard en La conquista espiritual de América, México, FCE, 1986.

\section{4}

María Sten, Vida y muerte del teatro náhuatl; el Olimpo sin Promeieo, México, Secretaría de Educación Pública, 1974, pág. 13

15

Aracil, op.cit., pág. 349.

La devoción popular guadalupana en la teatralidad mexicana MÓNICA RUIZ BAÑULS indio llamado Marcos» ${ }^{10}$. Bustamante juzga en dicho sermón como idolátrico el culto guadalupano pidiendo la inmediata intervención de las autoridades para erradicarlo; asimismo, acusa a Montúfar de ser divulgador de milagros obrados por la imagen colocada en la ermita de Tepeyac, sin previa comprobación de la autenticidad de esos prodigios. Para O'Gorman, se revela a partir de estas informaciones que «toda esa devoción no podía tener más antigüedad que la del señor Montúfar en el gobierno de la mitra de México» ${ }^{11}$.

Sin pretender abordar con exhaustividad esta polémica planteada por O'Gorman, lo que me interesa recuperar es la idea central que subyace a lo largo de toda su reflexión al plantear el origen de la advocación guadalupana como una respuesta concreta del episcopado y la corona española en su deseo de cohesionar a la población novohispana a partir de la religiosidad. Considero que es necesario advertir cómo dicho objetivo, que funcionó con relativa eficacia durante el proceso evangelizador, vuelve a ser recuperado durante la época de la Independencia y, como veremos a continuación, es rescatado de nuevo con fuerza en la actualidad con fines muy similares.

Ahora bien, volviendo a nuestra perspectiva de lectura, cabría preguntarse cuál es el hilo conductor del proceso de las representaciones navideñas que se inicia con la milagrosa aparición mariana en el Tepeyac y pervive hasta nuestros días. Como ha señalado Josefina Muriel, es necesario advertir que

... la vía que conduce a explicar este proceso es la presencia de la madre de Jesús. Esta figura impregnó gran parte del teatro y la poesía en el virreinato de la Nueva España. Al llegar a tierras de indios, los religiosos mendicantes que deseaban llevar a cabo la evangelización de inmediato, pensaron en influir en las mentalidades de los indígenas mediante los sentidos $y$, así, pusieron todos sus esfuerzos en tal intento: pintura, mural y arquitectura. El teatro fue entonces una forma didáctica y accesible de mostrar a los indios lo que había sido el cristianismo y los misterios que predicaban. Obviamente la figura de María era centra. ${ }^{12}$.

Así pues, no se puede obviar el hecho de que el evento guadalupano tuviese lugar en medio del proceso de evangelización novohispano, característico del tiempo y de las circunstancias de la llamada «conquista espiritual» ${ }^{13}$. Por todo ello, sus representaciones se han de vincular necesariamente con un marco más amplio como es el de la institucionalización del culto mariano entre los naturales y el del teatro evangelizador. Las representaciones teatrales llevadas a cabo por los franciscanos en Nueva España durante el siglo XVI obedecieron a objetivos muy concretos de adaptación del cristianismo a un entorno del todo nuevo y, por tanto, quedaron determinadas por los planteamientos y problemas propios de dicho proceso. En este sentido, las implicaciones no sólo religiosas sino también culturales e ideológicas de esta dramaturgia se presentan como un elemento destacado en el complejo proceso de aculturación que supuso todo el proyecto evangelizador.

A la conquista territorial del Nuevo Mundo le sucedió otra, la espiritual, en la que el teatro, como medio de difusión ideológica, desempeñó una labor determinante. Como ha explicado la investigadora María Sten,

...la conquista española difiere de otras empresas similares de su época y de épocas posteriores en la medida en que se usa, al lado de las armas tradicionales, un arma poco común: el teatro. Y se puede decir, sin exageración, que el teatro fue en la conquista espiritual de México, lo que los caballos y la pólvora fueron en la conquista militar ${ }^{14}$.

Dentro de ese teatro evangelizador, son diversas las obras en las que la figura de María queda ensalzada junto a la de su Hijo, siendo la alabanza a la Virgen uno de los intereses temáticos más recurrentes. Durante el siglo XVI, como ha señalado Beatriz Aracil, el aspecto que más se destacó de la Madre de Dios en muchas de las manifestaciones dramáticas fue «su papel como intercesora de la Humanidad, aspecto fácilmente observable en representaciones como la Comedia de los Reyes Magos, La educación de los bijos o Las ánimas $y$ las albaceas $»^{15}$. En cualquier caso, como señala esta investigadora, según los datos aportados por las crónicas de Motolinía y Ponce, los franciscanos dedicaron también piezas específicas a otros momentos fundamentales de la vida de la Virgen como la Anunciación y la Visitación de Nuestra Señora a Santa Isabel (Tlaxcala, 1538) y las dos representaciones conocidas de la Asunción de Nuestra Señora (Tlaxcala, 1538 y Zapotlán, 1587).

A partir del siglo XVII, la temática teatral mariana de intercesión maternal da paso a las apariciones milagrosas $y$, muy especialmente, a las intervenciones prodigiosas de la Virgen de Guadalupe. Dichas representaciones vendrán a enriquecer la temática del teatro 
religioso en lengua indígena y se llevarán a cabo para enseñar, difundir y ganar adeptos a la idea de la aparición de la Virgen a un sencillo indígena mexicano. Pieza modélica en este sentido vendría a ser la de El Portento Mexicano, representada por primera vez durante la época virreinal y cuya primera versión castellana completa se ha publicado recientemente $^{16}$. Como ha señalado Germán Viveros:

\section{Se conocen textos equiparables a El Portento Mexicano} que han ido transitando de generación en generación, pero que cada vez que son representados padecen la mano de un adaptador que, en afán de adecuarlo a su circunstancia, lo modifica sin el respeto debido al original que ha legado la tradición. No obstante, el texto de El Portento Mexicano, en el estado en que se encuentra, debió satisfacer ampliamente la finalidad educativo-religiosa para la que fue escrito ${ }^{17}$.

Así pues, la Virgen de Guadalupe aparece en el teatro mexicano prácticamente desde que éste nace: en primer lugar, como fruto de ese encuentro entre la tradición medieval europea y la indígena prehispánica que da lugar al drama misionero y, a continuación, como expresión esencial de un pueblo que intenta comprenderse y ponerse en relación con una nueva sociedad virreinal en la que las representaciones guadalupanas tendrán una presencia notable.

Para completar esta perspectiva de lectura de la guadalupana en la teatralidad mexicana, será necesario abordar brevemente cómo hacia finales del siglo XVIII se pasa de lo que se puede llamar una "mariofanía mexicana» a una "epifanía patriótica» ${ }^{18}$, es decir, cómo se produce una lenta evolución que convierte a la Virgen de Guadalupe en estandarte de la Independencia y símbolo por excelencia de la mexicanidad.

No se puede obviar que el teatro guadalupano es una de las tradiciones dramáticas más profundas del espíritu religioso nacionalista; son diversas las representaciones que surgen en esta época en torno a la Virgen de Guadalupe ${ }^{19}$, manifestaciones en las que se busca siempre el mismo efecto social: reafirmar una identidad diferente y promover su expresión ${ }^{20}$. Además de la importancia del mito guadalupano en la fundación del pueblo mexicano y su trascendencia hasta nuestros días, conviene señalar, como ha explicado Luis de Tavira, la importancia de esta tradición teatral religiosa que «si bien proviene de las corrientes medievales del teatro litúrgico, las renacentistas de la evangelización y las alegóricas del barroco, constituye una expresión privilegiada y estricta de lo nacional mexicano, propio, otro y exclusivo» ${ }^{21}$.
Así pues, en los inicios del México independiente, la Virgen de Guadalupe se convierte en la bandera de insurrección para la población criolla, en el emblema movilizador de una conciencia extendida por todo el territorio de la nación. Y si bien es cierto que todas estas representaciones pretenden reafirmar el culto guadalupano, más por motivos de conciencia nacionalista que por fervores religiosos, en mi opinión es evidente que no podemos dejar de vincularlas al marco de la devoción popular, ya que se hace necesario recordar que estamos en una situación extrema en la que

...se alentó una religiosidad primitiva casi siempre manifestada en celebraciones paralitúrgicas, con frecuencia heterodoxas, siempre sincréticas (...). La instrucción religiosa quedó circunscrita a la educación familiar y pertenecía al dominio y deber de las madres con los hijos durante la infancia. Así se creó una verdadera tradición oral que heredaba de padres a hijos las más remotas manifestaciones del fasto litúrgico barroco: pastorelas, vía crucis, pasiones, danzas de moros y cristianos, autos de milagros, apariciones y múltiples procesiones ${ }^{22}$.

Por tanto, estamos ante unas manifestaciones teatrales en las que juega un papel esencial la religiosidad popular de una época tan específica para la historia mexicana como ésta, aunque evidentemente difuminada por un complejo contexto social y político en el que la devoción mariana se transformó en un guadalupanismo nacionalista y utópico que luchaba por un México independiente y moderno.

\section{DEVOCIÓN POPULAR MARIANA: MARCO DE REFERENCIA DE LA TEA- TRALIDAD GUADALUPANA}

Al hablar de la piedad popular mariana, diversa en expresiones y profunda en sus causas, estamos haciendo referencia sin duda a uno de los hechos eclesiales más relevantes y universales. Como explica Rodríguez Becerra, la devoción mariana se sustenta en la idea popular de que «la Virgen no es sólo la Madre del Señor y del Salvador, sino también, en el plano de la gracia, la madre de todos los hombres ${ }^{23}$.

Considerando la teatralidad guadalupana como expresión esencial de la trayectoria

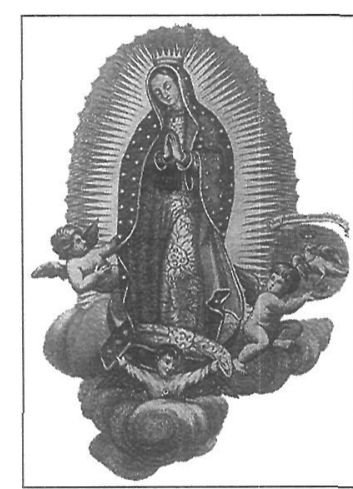

Manuel Rodríguez. Grabado en metal de la Virgen de Guadalupe con las armas mexicanas. sf.

18

Cit. en Jacques Lafaye, Quetzalcóatl y Guadalupe. La formación de la conciencia nacional de México, México, FCE, 1977, pág. 417

19

Armando de María y Campos recoge en su estudio dedicado al teatro guadalupano una larga lista de piezas dramáticas marianas y estrenos de esta época con dicha temática, títulos entre los que destacan representaciones como la Loa para celebrar a Nuestra Santísima Madre y Señora Santa María de Guadalupe (1794) y Loa para celebrar la maravillosa aparición de Nuestra Santísima Madre María de Guadalupe (1804) de Manuel Quiroz y Campa. Para más información véase María y Campos, op.cit., págs. 39-73.

20

Considero un ejemplo paradigmático de esta perspectiva de lectura que presento el Auto mariano. Para recordar la milagrosa aparición de Nuestra Madre y Señora de Guadalupe de José Joaquín Lizardi cuyo texto completo queda recogido en Luis de Tavira, (ed.), Autos, pasforelas y dramas religiosos (1817-1862). Teatro mexicano. Historia y dramaturgia, Volumen XI, México, Consejo Nacional para la Cultura y las Artes, 1994, págs. 47-59.

21

Ibidem, pág. 24.

22

Ibídem, pág. 20.

23

Álvarez Santaló, M. Buxó Rey y S. Rodríguez Becerra (coords.), La religiosidad popular, Barcelona, Anthropos, 2003, vol. I, pág. 27.
La devoción popular guadalupana en la teatralidad mexicana MÓNICA RUIZ BAÑULS 


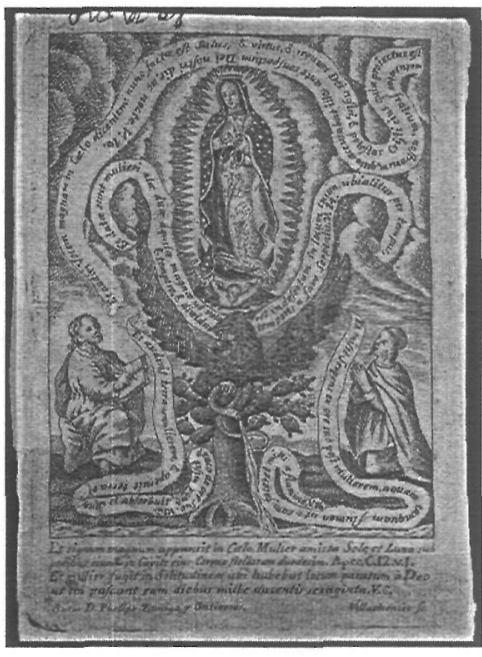

Guadalupe posada sobre las armas mexicanas y guarnecida por San Juan y Juan Diego. Miguel de Villavicencio. Siglo XVIII.

24

Ibídem, pág. 30.

25

Las fuentes de la tradición guadalupana se encuentran en lo que Francisco de la Maza llama «los cuatro evangelistas guadalupanos»: Imagen de la Virgen María de Dios de Guadalupe (1648) de Miguel Sánchez, el Nican Mopohua (à 1646?) de Antonio Valeriano, Felicidad de México en el principio y milagrosos origen del santuario de la Virgen de Guadalupe (1675) de Luis de Becerra y la Estrella del norte de México (1681) de Francisco de Florencia (cfr. Francisco de la Maza, El guadalupanismo mexicano, México, FCE, 1984, págs. 54-94). Como ha explicado Luis de Tavira, «en estos cuatro libros, articulados en un ritmo progresivo, se va conformando la narración ponderada que viene y va de la tradición oral y encuentra sus derivaciones y correspondencias en las Informaciones de 1666, en los sermones (...), en la poesía guadalupana del barroco novohispano $y$, desde luego, del teatro guadalupano desde el siglo XVI hasta el XX» (Tavira, op.cit., pág. 27).

\section{6}

Jesús de la Vega, Devoción popular guadalupana en México, Roma, Universitat Pontificia Salesiana, 2001, pág. 73

27

íbidem, pág. 78.

La devoción popular guadalupana en la teatralidad mexicana MÓNICA RUIZ BAÑULS del pueblo mexicano desde la época colonial, como forma de cohesión y definición de su identidad, estamos adentrándonos necesariamente en el ámbito de la religiosidad popular que, como todo ritual de carácter religioso, es un «complejo fenómeno polisémico que no sólo comunica un mensaje relacionado con lo sobrenatural sino también con lo económico, lo social, lo lúdico, lo étnico y con todo el sistema cultural de un pueblo» ${ }^{24}$. Desde esta perspectiva, considero necesario insertar las representaciones en torno a la Virgen de Guadalupe en el marco de la veneración y culto de esta advocación mariana, pues sólo desde la comprensión completa de esta devoción se puede comprender la vigencia actual de diversas manifestaciones teatrales en las que la Guadalupana sigue siendo símbolo cultural y religioso de todos los mexicanos.

Desde el momento en que la devoción guadalupana se convierte en una manifestación de la identidad colectiva, que no se limita a lo religioso, sino que, como hemos visto, abarca una dimensión social, ideológica y cultural, se hace conveniente señalar las diversas implicaciones que motivan su vigente presencia en las representaciones dramáticas populares. En este sentido hemos de tener en cuenta el hecho de que las primeras narraciones en torno al hallazgo y apariciones de la Virgen de Guadalupe ${ }^{25}$ fueran, a la vez que la justificación del cerro de Tepeyac como lugar de culto mariano, una creencia que la comunidad asumió como suplemento al dogma católico. Como explica Jesús de la Vega, el valor de verdad de tales relatos no podría ser cuestionado «sin cuestionar a la vez la credibilidad de la comunidad como tal. Es el mismo pueblo el que da forma a esas justificaciones y rescata la figura de la Virgen en sus diversas advocaciones volcando en ella toda su sensibilidad religiosa» ${ }^{26}$.

Teniendo esto presente y el hecho de que el catolicismo popular sigue siendo el sector más grande e importante de la religiosidad en el México de hoy, cuyo centro continúa situándose en la devoción guadalupana, no es de extrañar que estas informaciones recogidas a lo largo de los siglos hayan quedado absorbidas como material folklórico que sigue manifestándose en un tipo de teatralidad que refleja una forma de entender el mundo muy concreta y que todavía hoy perdura.
Asimismo, cabe advertir que, si partimos del hecho que el teatro nació en México como un discurso sincrético, fusión de la tradición medieval europea y la indígena prehispánica, la Virgen de Guadalupe como temática de la mencionada teatralidad se convierte en un eslabón esencial en la evolución de dicho mestizaje, ya que bajo esta advocación mariana no podemos ver un mero símbolo configurante de la identidad de un colectivo, sino la transformación de uno de los símbolos y expresiones esenciales de la identidad grupal del pueblo mexicano. Ello justifica la incursión de la piedad guadalupana en el marco de la devoción popular pues, como ha señalado de la Vega, podemos hablar de religiosidad popular en

...aquellas manifestaciones culturales, de carácter privado o comunitario, que en el ámbito de la fe cristiana, se expresan principalmente, no con los modos de la Sagrada Liturgia, sino con las formas peculiares derivadas del genio de un pueblo o de una etnia y de su cultura2?.

De este modo, si bien es cierto que la irrupción de la devoción mariana en el ámbito de la religiosidad popular surge de la fe cristiana, no hay duda de que ésta ha tomado en México una fisonomía particular que implica una reinterpretación muy concreta del hecho mariano: la fisonomía mestiza de María de Guadalupe. Esta reelaboración fue la que permitió aunar los rasgos identificadores de la comunidad indígena y la española, nuevas formas y antiguos significados vigentes en las diversas manifestaciones teatrales populares guadalupanas que todavía hoy nos hablan de la riqueza cultural del pueblo mexicano.

Finalmente, para comprender con nitidez el fenómeno de la devoción guadalupana y su vigencia actual en la teatralidad popular, cabe plantearse si esta presencia puede ser explicada por la creencia de la comunidad en dicha advocación mariana. Como hemos visto, es el mismo pueblo mexicano el que le ha ido dando forma y justificación a la figura de la Virgen de Guadalupe volcando en ella toda su sensibilidad religiosa. Cuestionarla sería cuestionar a la propia comunidad y su identidad. La interiorización del culto mariano viene por tradición familiar, es algo que «envuelve y sobrecoge a los miembros de la familia, pero además es anclaje de nacionalidad: unión parental, comunión patriótica, identidad comunitaria y recogimiento espiri- 
tual $\gg^{28}$. Por todo ello, considero que estamos ante una cuestión a la que no es posible dar una respuesta inequívocamente afirmativa o negativa. Como han señalado Torre Villar y Navarro de Anda:

\begin{abstract}
Si la aparición de la Virgen al indio Juan Diego es negada por quienes buscan explicaciones puramente cientificas y materiales, la fuerza espiritual que ha ejercido a lo largo del tiempo no ha podido soslayarse $\mathrm{y}$, aun cuando se interprete al tenor de explicaciones psicológicas y sociológicas, económicas y políticas de muy diverso signo, su existencia, la fuerza de su acción y sus manifestaciones, aun las materiales, son $\tan$ vivas que resulta imposible negarlas ${ }^{29}$.
\end{abstract}

Por tanto, instrumentalización política o cobijo espiritual comunitario, de lo que no hay duda es de que la figura de la guadalupana se presenta como «una de las primeras referencias en la endoculturación primaria del pueblo, estrechamente relacionada con la transmisión generacional, ámbito desde el cual se adquiere la sociabilidad y la identidad»30. Su presencia en diversas manifestaciones dramáticas a lo largo del acontecer histórico de México responde sin duda al hecho de que la teatralidad popular haya expresado siempre las luchas, tribulaciones y preocupaciones que han ido marcando el ritmo de las vivencias cotidianas e históricas de un pueblo.

Resulta evidente que la devoción a María de Guadalupe, enmarcada en el ámbito de la religiosidad popular, polariza muchos valores y actitudes de la vida diaria de una comunidad, no sólo en su dimensión creyente, sino también en su dimensión cultural y social. Como hemos visto, el evento guadalupano ha formado parte de aquellos momentos importantes y de gran significación para la formación de la identidad mexicana: desde el papel relevante de la aparición de la imagen en la primera evangelización, acontecimiento que polarizó en gran medida el mensaje cristiano y que selló toda la pedagogía misionera, hasta la contribución indudable en la formación de la conciencia nacional y el sentimiento patriótico.

De este modo, el pueblo mexicano acabó haciendo suyo el mensaje de la Virgen de Guadalupe, no sólo como elemento vital de su fe sino como signo de unidad nacional y símbolo por excelencia de la mexicanidad. Más allá del fenómeno y del sentimiento religioso, hay una realidad como emblema nacional insoslayable; como explica Fernández Poncela,

...sea invención o no, eso es lo que menos importa, lo destacable es el consenso en este sentido, donde las dudas se desvanecen y la claridad deja atrás a las sombras, y ése si que existe como símbolo de México por encima de todo y de todos. Es prolongación de la identidad: como pertenencia e identificación con y a la vez diferenciación de ${ }^{31}$.

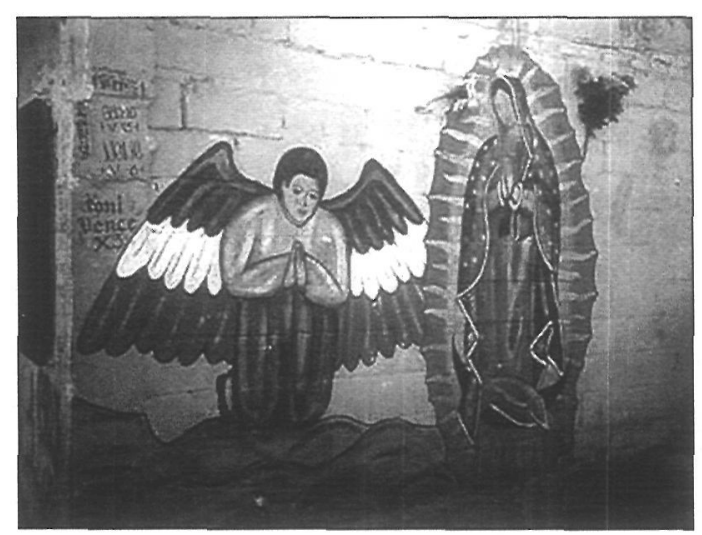

Pintura mural popular (arte chicano). Siglo XX.
En definitiva, como hemos podido observar, aproximarse al hecho guadalupano supone enfrentarse a un fenómeno cultural de gran complejidad: símbolo de la fe cristiana de los españoles durante la evangelización y absorbido después como sustancia folklórica en el ámbito popular indígena, acabará convirtiéndose en estandarte de la Independencia para llegar a nuestros días no como una formulación teológica o ideológica, sino como una imagen colectiva profundamente urdida a través de las fiestas religiosas, los avatares históricos, las costumbres y, por supuesto, la teatralidad popular.

\section{BIBLIOGRAFÍA}

Álvarez Santaló, C., Buxó Rey, M., y Rodríguez Becerra, S. (coords.), La religiosidad popular, Barcelona, Anthropos, 2003, 3 vols.

Aracil Varón, María Beatriz, El Teatro evangelizador: sociedad, cultura ideología en la Nueva España del siglo XVI, Roma, Bulzoni, 1999.

Arrom, Juan José, El teatro de Hispanoamérica en la época colonial, La Habana, Anuario Bibliográfico Cubano, 1956.

Congregación para el Culto Divino, Directorio sobre la piedad popular y la liturgia. Principios y orientaciones, Madrid, BAC, 2002.

Fernández Poncela, Anna, «Semantización política y personal de una imagen: la Virgen de Guadalupe», Cuicuilco, México, INAH, 2000, vol. VII, núm. 20, págs. 137-143.

Horcasitas, Fernando, «Las piezas teatrales en lengua náhuatl. Bibliografía descriptiva», Boletín Bibliográfico de Antropología (México), 1948, núm. XI, págs. 154-164.
28

Anna Fernández Poncela, «Semantización política y personal de una imagen: la Virgen de Guadalupe», Cuicuilco, México, INAH, 2000, vol. VII, núm. 20, pág. 141.

29

Ernesto de la Torre Villar y Ramiro Navarra de Anda, Testimonios históricos guadalupanos, México, FCE, 1982, pág. 8.

30

Fernández Poncela, op. cit., pág. 142.

31

Ibidem, pág. 147. 
Horcasitas, Fernando, Teatro nábuatl II, coord. por María Sten y Germán Viveros, México, UNAM, 2004.

Lafaye, Jacques, Quetzalcóatl y Guadalupe. La formación de la conciencia nacional de México, México, FCE, 1977.

León-Portilla, Miguel, Tonatzin-Guadalupe. Pensamiento nábuatl y mensaje cristiano en el «Nican Mopobua», México, FCE, 2002.

Lucas Anaya, José, La milagrosa aparición de la Nuestra Señora María de Guadalupe de México, México, UNAM, 1995.

María y Campos, Armando de, La Virgen frente a las candilejas o El teatro guadalupano, México, Ediciones Populares, 1954.

Maza, Francisco de la, El guadalupanismo mexicano, México, FCE, 1984.

Muriel de la Torre, Josefina, La tradición de las pastorelas mexicanas, México, Ediciones Olivo, 1996.
Noguez, Xavier, Documentos guadalupanos, México, FCE, 1995.

O'Gorman, Edmundo, Destierro de sombras. Luz en el origen de la imagen y culto de Nuestra Señora de Guadalupe del Tepeyac, México, UNAM, 1986.

Ricard, Robert, La conquista espiritual de América, México, FCE, 1986.

Tavira, Luis de (ed.), Autos, pastorelas y dramas religiosos (1817-1862). Volumen $X I$. Teatro mexicano. Historia y dramaturgia, México, Consejo Nacional para la Cultura y las Artes, 1994.

Torre Villar, Ernesto de la y Navarro de An$\mathrm{da}$, Ramiro, Testimonios bistóricos guadalupanos, México, FCE, 1982.

Vega, Jesús Hector de la, Devoción popular guadalupana en México, Roma, Universitat Pontificia Salesiana, 2001. 